\title{
Luxatio Erecta: Case Report
}

\author{
Lamkhanter A*, Zadoug O, Ouzaa MR, J alal Y, \\ Antri I, Bensaleh R, Ibo N, Bouya A, El Ghoul N, \\ Elghazoui A, , Bennis A, Benchekroune M, Zine A, \\ Tanane $M$ and J aafar $\mathbf{A}$ \\ Department of Orthopedic Surgery and Traumatology \\ I, Mohammed V Military Training Hospital of Rabat, \\ Faculty of Medicine and Pharmacy of Rabat, Mohammed \\ V University of Rabat, Morroco \\ *Corresponding author: Adil Lamkhanter, \\ Department of Orthopedic Surgery and Traumatology, \\ Mohammed V Military Training Hospital of Rabat, \\ Faculty of Medicine and Pharmacy of Rabat, Mohammed \\ V University of Rabat, Morroco
}

Received: February 27, 2018; Accepted: March 22,

2018; Published: March 29, 2018

\section{Introduction}

Luxatio Erecta Humeri (LEH) is the rarest type of shoulder dislocation. It represents $0.5 \%$ of all shoulder dislocations [1]. The first description of this variety has been in 1859 by Middel dorpf and Scharm [2]. Clinically, it's characterized by hyper abduction of the affected arm, flexion of the elbow and pronation of the forearm. The diagnosis is confirmed by antero posterior radiograph. This entity is frequently associated with neurovascular injuries. Concomitant fracture of clavicle, coracoid, greater tuberosities were also described. Early reduction should be done to prevent complications. We present a case of pure luxatio erecta, with discussion of the mechanism, clinical, radiographic and therapeutic features.

\section{Case Presentation}

A 60-year-old man who presented to the emergency department after falling several steps, causing pain and functional impotence of the right upper limb. Once admitted, the patient was conscious and cooperative. Upon physical examination, the right humerus was removed, the elbow flexed and the left hand resting on his forehead. He was unable to bring the elbow back to the body. No evidence of neurovascular compromise was noted (Figure 1). Radiological assessments of the right shoulder (plain X-ray and CT scan) revealed lower glenohumeral dislocation (Figure 2,3).

The closed reduction was performed by a pull-and-pull method under general anesthesia and confirmed by radiography, which showed an anatomical reduction of the glenohumeral (Figure 4). After reduction, the brachial, radial and ulnar impulses were palpable, and no motor or sensory deficit was detected. Immobilization bends to the body for 3 weeks, followed by physical rehabilitation of the right shoulder

\section{Discussion}

Luxatio erecta, or inferior shoulder dislocation, is the least common of shoulder dislocations representing only $0.5 \%$ of cases, with no age predilection [3]. Davids and Talbott [4] reported two mechanisms of luxation erecta. A direct dislocation results from an

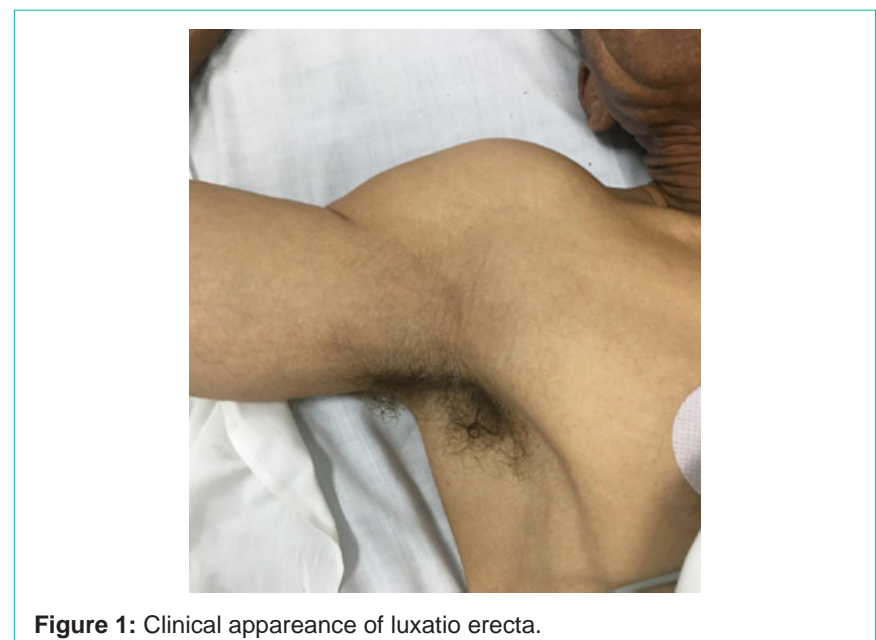

Figure 1: Clinical appareance of luxatio erecta.

axial loading to a fully abducted arm. An indirect dislocation, which is more common, is the result of a hyper abduction combined with external rotation.

The classic clinical finding is the arm locked in abduction, the elbow in flexion and the forearm behind the head, and any attempts to move is resulted in intense pain [5]. Our patient had similar presentation as described. The radiologic presentation of luxatio erecta is classically with the humeral head displaced directly below, and a little medial to the glenoid fossa, with the arm often in marked abduction. Fractures of the scapula or humeral head may also be seen, particularly of the greater tuberosity as in this case. "However, computed tomography is a better tool to evaluate associated fine fractures [6], and magnetic resonance imaging better reveals the injuries to the rotator cuff, the labrum, and the ligaments [7].

Closed reduction with appropriate analgesia should be chosen first in the emergency department. There are multiple reduction techniques available, the most common being the "opposite traction" technique described by Freundlich [8]. The second one consists to converting inferior dislocation to an anterior shoulder dislocation 


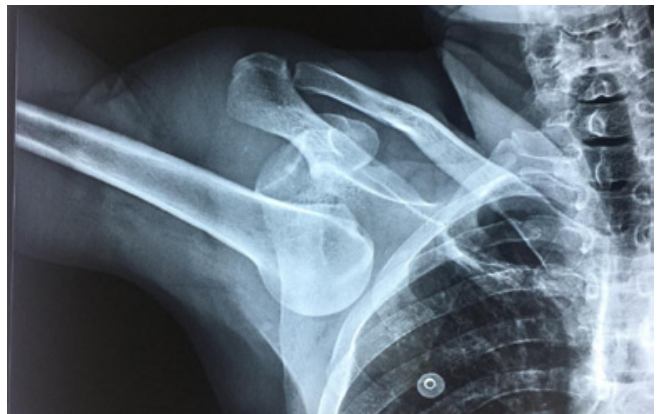

Figure 2: Anteroposterior radiograph of luxatio erecta.

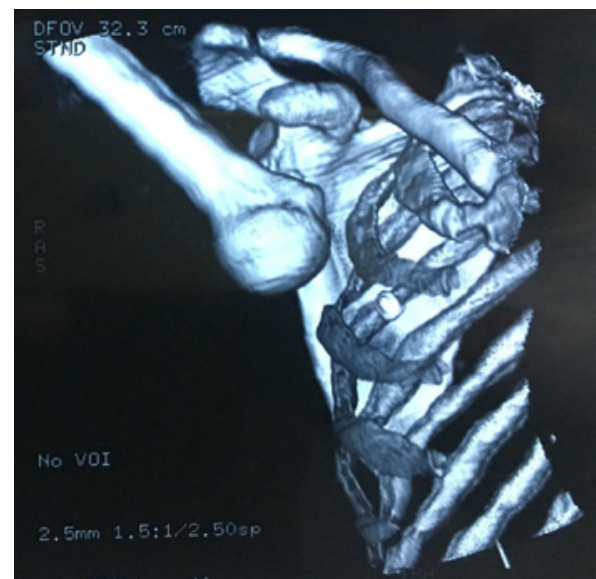

Figure 3: CTM view showing pure luxatio erecta.

[9]. However, unsuccessful closed reduction from entrapment of the joint capsule, or the presence of vascular injury may necessitate open reduction. In our case presented above, the closed reduction was achieved by traction-counter traction.

When the dislocation has been reduced the joint should be examined and xrayed once again to ensure successful reduction and evaluate for iatrogenic neurovascular injury or fracture.

Many complications of an inferior glenohumeral dislocation have been noted in the literature. Malon and al reported that 60 of cases manifested neurologic injuries most frequently to the circumflex nerve [1]. These injuries resolve generally after successful reduction. Several vascular injuries may be associated with luxation erecta most commonly to the axillary artery. However, the incidence of these injuries is low 3,3\%. In addition, musculoskeletal injuries including rotator cuff tears, Fractures of the acromion, clavicle, inferior glenoid fossa and greater tuberosity are more frequent than other complications. In our case, after reduction, any neurovascular injuries noted, and the the $\mathrm{x}$-ray Postreduction confirm a relocation of the dislocation.

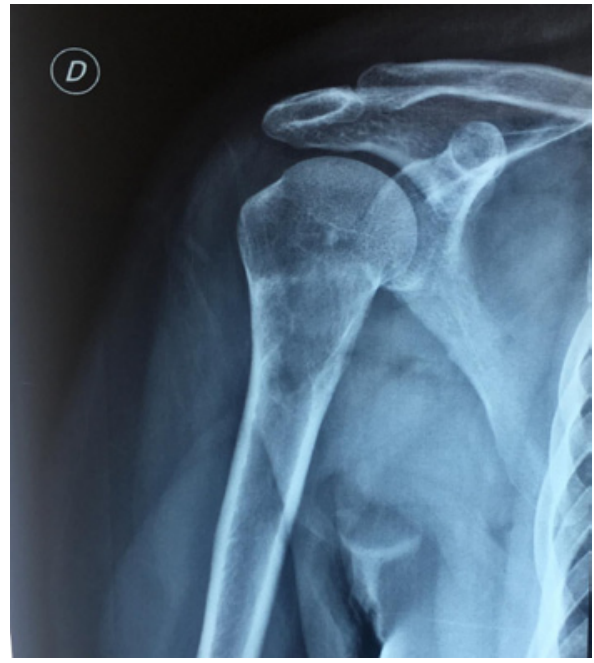

Figure 4: The radiograph confirming successful reduction.

\section{Conclusion}

The Luxatio erecta is the rare form of shoulder dislocations. The clinical presentation is unmistakable. The anteropsterior radiograph confirms the diagnosis and assesses other bone fracture. Early reduction should be done to prevent complications. The functional long-term prognosis is excellent.

\section{References}

1. Mallon WJ, Bassett FH, 3rd, Goldner RD. Luxatio erecta: the inferior glenohumeral dislocation. J Orthop Trauma. 1990; 4: 19-24.

2. Middeldorpf M, Scharm B. Denova humeri luxationis specie. Clin Eur. 1859; 2: 12 .

3. Brady WJ, Knuth CJ, Pirallo RG. Bilateral inferior glenuhumeral dislocation: luxation erecta, an unusual Presentation of A rare Disorder. J Emerg Med. 1995; 13: 37-42

4. Davis RJ, Talbot DR. Luxatio Humeri. clin. ortho erecta and Rel Res. 1990; 252: 144-148.

5. Muzaffar N, Ahmad N, Ahmad A, Ahmad N. Luxatio erecta: a rare case of inferior dislocation of the shoulder. WebmedCentral Orthopaedics. 2011; 2: WMC002156.

6. Imerci A, Golcuk Y, Ugur SG, Ursavas HT, Savran A, Surer L. Inferior glenohumeral dislocation (luxatio erecta humeri): report of six cases and review of the literature. Ulus Travma Acil Cerrahi Derg. 2013; 19: 41-44

7. Krug DK, Vinson EN, Helms CA. MRI findings associated with luxatio erecta humeri. Skeletal Radiol. 2010; 39: 27-33.

8. Freundlich BD. Luxatio erecta. J Trauma. 1983; 23: 434-436.

9. Nho SJ, Dodson CC, Bardzik KF, Brophy RH, Domb BG, MacGillivray JD. The two-step maneuver for closed reduction of inferior glenohumeral dislocation. J ortho trauma. 2006; 20 : 354-357
Austin J Orthopade \& Rheumatol - Volume 5 Issue 1 - 2018 ISSN: 2472-369X | www.austinpublishinggroup.com Lamkhanter et al. (C) All rights are reserved
Citation: Lamkhanter A, Zadoug O, Ouzaa MR, Jalal Y, Antri I, Bensaleh R, et al. Luxatio Erecta: Case Report. Austin J Orthopade \& Rheumatol. 2018; 5(1): 1065. 